\title{
FORMULATION AND EVALUATION OF POLYHERBAL FLOATING EFFERVESCENCE TABLET CONTAINING PEDALIUM MUREX AND TRIBULUS TERRESTRIS FRUIT EXTRACTS
}

\author{
CHITRA DEVI VENKATACHALAM1* ${ }^{*}$, MOTHIL SENGOTTIAN ${ }^{1}$, TAMIZHARASI SENGODAN²
}

${ }^{1}$ Department of Chemical Engineering, Kongu Engineering College, Erode, Tamil Nadu, India, ${ }^{2}$ Department of Pharmaceutics, Nandha College of Pharmacy, Erode, Tamil Nadu, India

Email: erchitrasuresh@gmail.com

Received: 24 Nov 2016, Revised and Accepted: 02 Mar 2017

\section{ABSTRACT}

Objective: The present investigation was based on the design and evaluation of floating tablets of Pedalium murex and Tribulus terrestris fruit extracts as the medicinal source and the excipients that can enhance the bioactivity and prolong the gastric retention time.

Methods: The fruit extracts were prepared from the powdered dry fruits of Pedalium murex and Tribulus terrestris using Soxhelt apparatus for 8 h. direct compression technique was used for the formulation of polyherbal floating effervescence tablets which consists of different compositions of Hydroxy Propyl Methyl Cellulose (HPMC K4M, HPMC K15M), Micro Crystalline Cellulose (MCC) and Sodium bicarbonate (NaHCO 3 ). The formulations were evaluated for thickness, hardness, friability, average weight variation, drug content, floating lag time, duration of floating and in vitro drug release. The data obtained from the in vitro dissolution studies were fitted in different models.

Results: All the tablets were satisfactory during the preformulation studies while F11 polyherbal formulation showed the maximum floating time of $15 \mathrm{~h}$, minimum floatation lag time of $35 \mathrm{~s}$ and drug release of $100.12 \%$. The dissolution kinetic studies for the optimum formulation was found to follow Korsemeyer and Peppas model with $\mathrm{R}^{2}$ value, rate constant $\mathrm{K}_{\mathrm{K}}$ and $\mathrm{n}$ as $0.9819,1.0492$ and 1.7385 respectively with a significance of $\mathrm{P}<0.05$ and showed better results compared to that of film coated herbal tablets.

Conclusion: Thus this polyherbal floating effervescence tablets can be used not only as an effective drug release method for herbal drugs to enhance their bioactivity but also as a replacement for film coated herbal tablets.

Keywords: Pedalium murex, Tribulus terrestris, Gastric retention time, Polyherbal floating effervescence tablet, Hydroxypropyl methyl cellulose

(C) 2016 The Authors. Published by Innovare Academic Sciences Pvt Ltd. This is an open access article under the CC BY license (http://creativecommons.org/licenses/by/4.0/) DOI: http://dx.doi.org/10.22159/ijap.2017v9i2.16319

\section{INTRODUCTION}

From earliest times plants has been used by mankind in an attempt to cure diseases, disorders and relieve physical pain and suffering. The knowledge on the medicinal properties of the plants was found out using trial and error method. It was found that most of the storage organs of the plants such as roots, seeds, leaves, bark, wood, or other parts of the plant are used as medicine [1]. The plant tissues consist of flavonoids, alkaloids, glycosides, phenols, saponins, tannins and steroids that are responsible for its medicinal value [2].

Pedalium murex Linn (family: Pedaliaceae) commonly known as 'large caltrops' is a shrub found in tropical Africa and in arid and coastal regions of India, Pakistan and Srilanka [3]. It grows up to 2 to 3 feet having irregularly shaped leaves and bear small yellow coloured flowers as in fig. 1(A). The fruits are pale yellowish brown colour, 4 angled indehiscent and hard pyramidal with 4 sharp spines as in fig. 1(B). The powder is dark brown and is rich in flavonoids, sapogenin and several alkaloids like pedalithin, diosmetin, dinatin, pedalin dinatin-7-glucuronide [4-6]. Pedalium murex is considered to be demulcent and diuretic, antispasmodic, aphrodisiac improves appetite, and reduces strangury, urinary discharges, vesical calculi, cough, asthma, skin diseases and heart trouble. $[7,8]$.

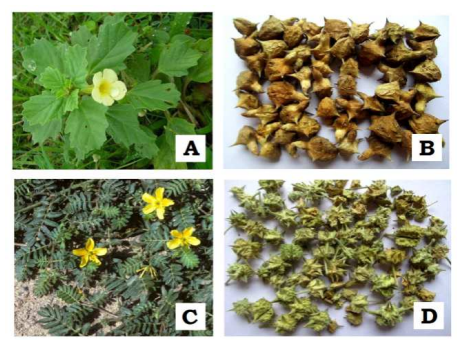

Fig. 1: Pedalium murex A) plant B) dried fruits, Tribulus terrestris $\mathrm{C}$ ) plant $\mathrm{D}$ ) dried fruits
Source: Herb sheet 3230 and 4420, Digital Flora of Karnataka by Herbarium JCB is licensed under a Creative Commons AttributionNon Commercial-ShareAlike 4.0 International License. URL: http://florakarnataka.ces.iisc.ernet.in.

Tribulus terrestris is commonly known as puncture vine grows to a height of 1 to 2 feet with pinnate compound leaves and yellow flowers as in fig. 1(C). The fruits are stellate shaped five segmented carpels with short stiff spines as in fig. 1(D). The fruit powder is greyish brown and contains flavonoids, alkaloids, glycosides, steroids and saponin derivatives like tigogenin, hecogenin, diosgenin, ruscogenin, chlorogenin and sarsasapogenin and sulphatedfuro and spiro saponins [10,11] Tribulus terrestris is used in folk medicine in the form of tonic as an aphrodisiac, analgesic, astringent, stomachic, antihypertensive, diuretic, lithontriptic and urinary anti-infective $[12,13]$.

Ayurvedic formulations that can be taken as internal medicine are generally classified into pattika (tablet), churna (powder), ashava/arista (fermented preparations), vati/guggulu preparations (resin), ghrita preparations (ghee based) and bhasma/rasha (calcinated products). Each dosage form has its own method of ingestion and has a different response time and drug retention time [14].

The present investigation was intended to formulate and evaluate the polyherbal formulation containing Pedalium murex and Tribulus terrestris fruit extracts. The polyherbal effervescence tablet formulation comes under the classification of pattika and is a combination of Ayurvedic plant drug and acts as the replacement for the currently marketed film coated herbal tablets. Effervescent mixtures help in masking the objectionable taste of the herbal drugs and provide a pleasant taste due to carbonation [15].

\section{MATERIALS AND METHODS}

\section{Materials}

Pedalium murex and Tribulus terrestris dried fruits obtained from the local market and the plants obtained from Nadarmedu, Erode, Tamil 
Nadu, India were compared and identified by Dr. N. Anjanadevi, Department of Botany, Vellalar College for Women, Erode, Tamil Nadu, India. They were also submitted and authenticated by Mr. Rakesh G. Vadhyar, Botanical Assistant, Botanical Survey of India Southern Regional Centre, Coimbatore, Tamil Nadu. The dried fruits of Pedalium murex and Tribulus terrestris were crushed using the hammer mill to remove the hard exoskeleton and then, it was pulverized using mixer grinder. The powder from the grinded mass was removed using sieve shaker and particles that passed through mesh no. $20(0.841 \mathrm{~mm})$ were collected and used for the study. Pharmaceutical grades of hydroxypropyl methylcellulose (HPMC K4M, HPMC K15M) from Otto Chemie Pvt Ltd., Mumbai, microcrystalline cellulose (MCC), sodium bicarbonate $\left(\mathrm{NaHCO}_{3}\right)$, magnesium stearate and talc were utilized in this study.

\section{Preparation of extracts [16]}

About 15 grams of powder was used for extraction in Soxhlet apparatus with different solvents namely ethanol, methanol, nhexane and petroleum ether separately. All extracts were concentrated using hot air oven and the residue was dried in a desiccator. This residue acts as the medicinal ingredient to the tablet. The solvent with the higher yield is used for further studies. The absorption maximum of the extracts dissolved in $0.1 \mathrm{~N} \mathrm{HCl}$ was studied between $400-700 \mathrm{~nm}$ regions using Elico double beam UVvisible spectrophotometer.

\section{FT-IR studies and phytochemical screening [17]}

Both the Pedalium murex and Tribulus terrestris fruit extracts were tested using Fourier transform infrared (FT-IR) Spectroscopy to confirm the presence of phytochemicals in the sample.

\section{Preparation of polyherbal tablet [18-20]}

The different ingredients for formulations are given as in table 1 below. The measured quantities of drug, HPMC, MCC and $\mathrm{NaHCO}_{3}$ were mixed thoroughly using a mortar and pistil. In order to obtain the granules, the mixture was passed through the $20 \mathrm{~mm}$ sieves. The granules were dried in a hot air oven and at last talc and magnesium stearate were added to the blend.

Table 1: Formulation of polyherbal effervescence floating tablet

\begin{tabular}{|c|c|c|c|c|c|c|c|c|c|c|c|c|}
\hline Ingredients (mg) & F1 & F2 & F3 & F4 & F5 & F6 & F7 & F8 & F9 & F10 & F11 & F12 \\
\hline Drug & 80 & 80 & 80 & 80 & 80 & 80 & 80 & 80 & 80 & 80 & 80 & 80 \\
\hline HPMC K4M & --- & --- & 120 & 120 & --- & --- & 140 & 140 & --- & --- & 160 & 160 \\
\hline HРMC K15M & 120 & 120 & --- & --- & 140 & 140 & --- & --- & 160 & 160 & --- & --- \\
\hline MCC & 165 & 130 & 165 & 130 & 145 & 110 & 145 & 110 & 125 & 90 & 125 & 90 \\
\hline $\mathrm{NaHCO}_{3}$ & 125 & 160 & 125 & 160 & 125 & 160 & 125 & 160 & 125 & 160 & 125 & 160 \\
\hline Talc & 5 & 5 & 5 & 5 & 5 & 5 & 5 & 5 & 5 & 5 & 5 & 5 \\
\hline Magnesium stearate & 5 & 5 & 5 & 5 & 5 & 5 & 5 & 5 & 5 & 5 & 5 & 5 \\
\hline Total & 500 & 500 & 500 & 500 & 500 & 500 & 500 & 500 & 500 & 500 & 500 & 500 \\
\hline
\end{tabular}

*HPMC-Hydroxy propyl methyl cellulose, MCC-Micro crystalline cellulose

The granules were punched into tablets using direct compression technique. The blank formulation (or) placebo (HPMC+ $\mathrm{MCC}+\mathrm{NaHCO}_{3}$ ) and polyherbal formulation were also tested using FTIR Spectrometer.

The standard parameters that have to be evaluated for prepared tablets were namely weight variation, hardness, friability, disintegration time and stability. In weight variation study, a random sample of twenty tablets was selected and the average weight was calculated. Then this weight was compared with individual tablets weight. The hardness was measured using Pfizer hardness, where the tablets were placed in contact between the plungers and the force of the fracture was recorded. The friability was determined using Roche friabilator at a constant rpm. Six tablets from each formulation were tested.

\section{Evaluation methods for polyherbal floating tablets}

\section{In vitro buoyancy studies [21]}

The Polyherbal tablet was placed in a $100 \mathrm{ml}$ beaker containing 0.1 $\mathrm{N} \mathrm{HCl}$. The time taken for the tablet to rise and float on the surface as floating lag time. The experiments were conducted in triplicate. Polyherbal effervescence tablet generates $\mathrm{CO}_{2}$ gas thereby reducing the density and hence it remains buoyant for a prolonged time period releasing the drug slowly at the desired rate.

\section{In vitro dissolution studies [22, 23]}

The release rate of polyherbal floating tablets was determined. The dissolution test was performed using United States Pharmacopeia (USP) type II paddle apparatus with an agitation speed of $50 \mathrm{rpm}$ in $0.1 \mathrm{~N}$ HCL maintained at $37 \pm 0.5^{\circ} \mathrm{C}$. At appropriate time intervals, the samples were withdrawn and assayed spectrophotometrically using Elico double beam UV-visible spectrophotometer at $\lambda$ max after filtration through Whatman filter paper and with suitable dilutions. The methodology for in vitro dissolution was kept the same for all the batches prepared. The experiment was done in triplicates.

\section{Rate kinetic studies [24]}

The release rate kinetics of the formulations was analyzed and the data obtained were fitted into Zero order, First order, Higuchi model and Kozmeyer Peppas model using equations in table 2.

Table 2: Mathematical Models for drug dissolution

\begin{tabular}{lll}
\hline Model & Mathematical equation & Release mechanism \\
\hline Zero Order & $\mathrm{C}=\mathrm{C}_{0}-\mathrm{K}_{0} \mathrm{t}$ & Diffusion Mechanism \\
First Order & $\log \mathrm{C}=\log \mathrm{C}_{0}-\mathrm{K}_{1} \cdot \mathrm{t} / 2.303$ & Fick's first law, diffusion mechanism \\
Higuchi Model & $\mathrm{Q}_{0} / \mathrm{Q}_{\mathrm{t}}=\mathrm{K}_{\mathrm{H}} \cdot \mathrm{t}^{1 / 2}$ & Diffusion medium based mechanism in Fick's first law \\
Kozmeyer Peppas Model & $\mathrm{Ct} / \mathrm{C}_{\infty}=\mathrm{K}_{\mathrm{K}} \cdot \mathrm{t}^{\mathrm{n}}$ & Semi-empirical model, diffusion based \\
\hline
\end{tabular}

\section{RESULTS AND DISCUSSION}

It was found that the ethanol produces the maximum yield of $6.5 \%$ and $12.3 \%$ for Pedalium murex and Tribulus terrestris respectively. The wavelength of maximum absorbance ( $\lambda$ max) for Pedalium murex and Tribulus terrestris were found to be 666 $\mathrm{nm}$ in $0.1 \mathrm{~N} \mathrm{HCl}$.

\section{FT-IR spectral studies}

From the FT-IR Spectroscopy reports shown in fig. 2, it is clear that both Pedalium murex and Tribulus terrestris are rich in phytochemicals such as phyto-steroids, flavonoids, alkaloids, sapogenin and glycosides. The report also depicts that there are no interactions and also the drug and polymer are compatible to develop a stable product. 

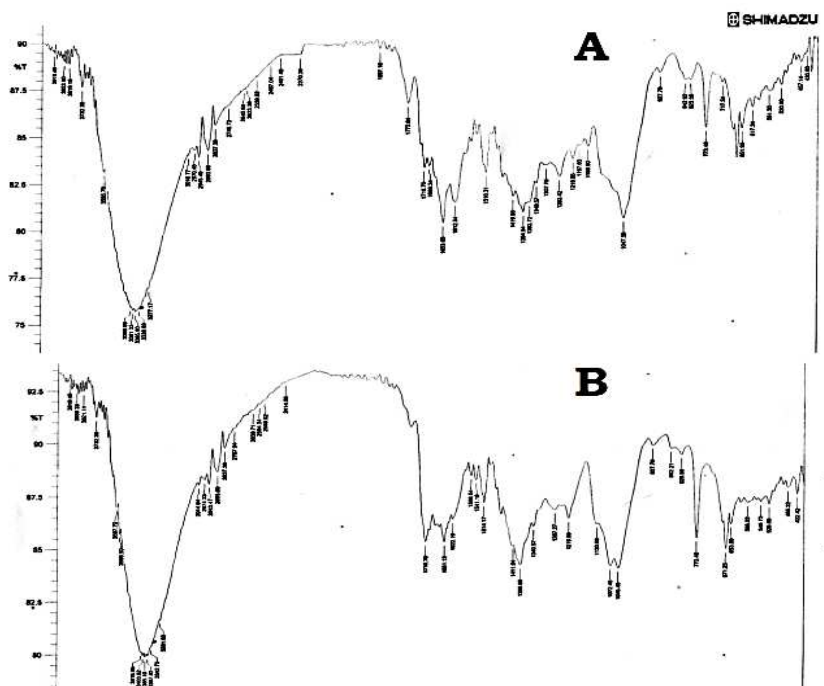

B

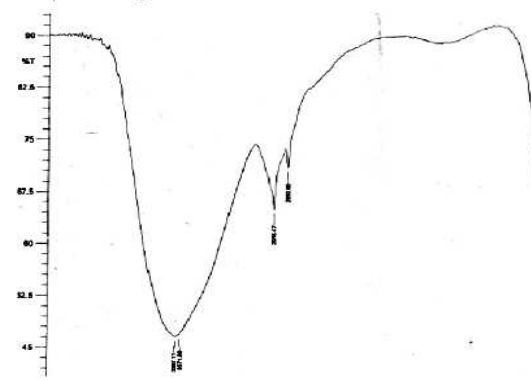

$\mathbf{C}$
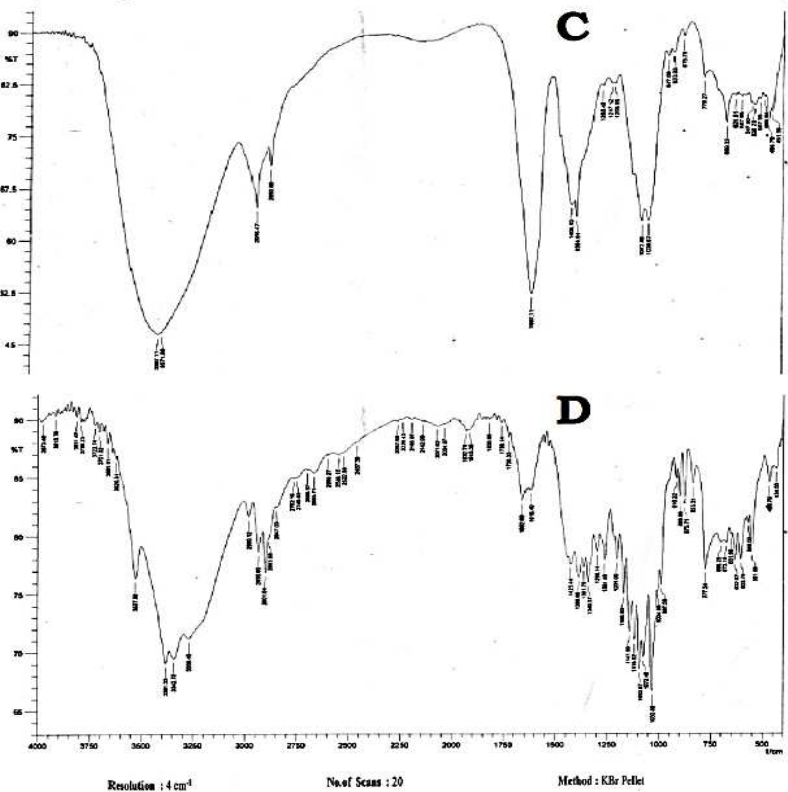

Fig. 2: FTIR Spectroscopy A) Pedalium murex B) Tribulus terrestris C) HPMC+MCC+NaHCO 3 D)Polyherbal formulation

\section{Preformulation studies}

The pre-formulation study results obtained on various parameters on granules were found satisfactory. The granules obtained for the batches (F1-F12) were satisfactory. No rat holing, capping or sticking was observed during the flow of granules from the hopper.
The compressibility index and Hausner's ratio values obtained for granules of all the batches and were found to be in the range of $14.36-17.96$ and $1.167-1.219(<1.25)$ respectively as shown in table 3 . The prepared tablets were greenish brown coloured with a smooth surface having acceptable elegance.

Table 3: Evaluation parameter of powder blend

\begin{tabular}{|c|c|c|c|c|c|c|}
\hline & Angle of repose degree ${ }^{\circ}$ & $\begin{array}{l}\text { LBD } \\
\mathrm{gm} / \mathrm{cm}^{2}\end{array}$ & $\begin{array}{l}\text { TBD } \\
\mathrm{gm} / \mathrm{cm}^{2}\end{array}$ & Compressibility index \% & Hausner's ratio & Flow character \\
\hline F1 & 34.7 & 0.485 & 0.575 & 15.65 & 1.185 & Good \\
\hline F2 & 35.1 & 0.484 & 0.585 & 17.26 & 1.208 & Fair \\
\hline F3 & 35.6 & 0.478 & 0.582 & 17.87 & 1.217 & Fair \\
\hline F4 & 35.6 & 0.488 & 0.592 & 17.57 & 1.213 & Fair \\
\hline F5 & 35.1 & 0.495 & 0.578 & 14.36 & 1.167 & Good \\
\hline F6 & 34.2 & 0.487 & 0.572 & 14.86 & 1.174 & Good \\
\hline F7 & 34.6 & 0.492 & 0.581 & 15.31 & 1.181 & Good \\
\hline F8 & 35.5 & 0.485 & 0.579 & 16.23 & 1.194 & Fair \\
\hline F9 & 35.3 & 0.491 & 0.575 & 14.61 & 1.171 & Good \\
\hline F10 & 34.3 & 0.475 & 0.579 & 17.96 & 1.219 & Fair \\
\hline F11 & 35.1 & 0.494 & 0.583 & 15.26 & 1.180 & Good \\
\hline F12 & 35.5 & 0.490 & 0.581 & 15.66 & 1.186 & Good \\
\hline
\end{tabular}

(Number of experiments n=3, mean), LBD-Loose Bulk Density, TBD-Tapped Bulk Density 


\section{Post compressional parameters}

The maximum weight variation of the tablets was $\pm 1.8 \%$, which falls within the acceptable range of $\pm 5 \%$, hence the tablets passed the weight variation test. Hardness for tablets of all batches was in the range of 4.92 to $5.35 \mathrm{~kg} / \mathrm{cm}^{2}$, which falls above the limit of not less than $3.0 \mathrm{~kg} / \mathrm{cm}^{2}$. Friability value for tablets of none of the batch was more than $0.37 \%$. The thickness of the tablets of all the batches was found in the range of 4.77-4.82 $\mathrm{mm}$ indicating fairly acceptable tablets as shown in table 4 .

Table 4: Evaluation parameter of tablet

\begin{tabular}{llllll}
\hline \multicolumn{7}{l}{ Evaluation parameters } & & \\
\hline & Thickness (mm) & Hardness (kg/cm2) & Friability (\%) & Average weight variation \\
\hline F1 & $4.65 \pm 0.096$ & $5.10 \pm 0.191$ & $0.36 \pm 0.010$ & $500.1 \pm 1.304$ & Drug content (\%) \\
F2 & $4.68 \pm 0.090$ & $5.01 \pm 0.254$ & $0.34 \pm 0.013$ & $500.7 \pm 1.795$ & $100.02 \pm 0.334$ \\
F3 & $4.72 \pm 0.128$ & $4.92 \pm 0.157$ & $0.37 \pm 0.017$ & $499.0 \pm 1.633$ & $100.00 \pm 0.191$ \\
F4 & $4.69 \pm 0.130$ & $5.27 \pm 0.275$ & $0.33 \pm 0.027$ & $499.7 \pm 1.247$ & $100.07 \pm 0.304$ \\
F5 & $4.78 \pm 0.111$ & $5.18 \pm 0.219$ & $0.37 \pm 0.016$ & $500.3 \pm 1.699$ & $100.03 \pm 0.320$ \\
F6 & $4.73 \pm 0.118$ & $5.35 \pm 0.096$ & $0.35 \pm 0.019$ & $500.6 \pm 1.367$ & $100.18 \pm 0.121$ \\
F7 & $4.65 \pm 0.108$ & $5.33 \pm 0.197$ & $0.33 \pm 0.019$ & $500.1 \pm 0.837$ & $100.10 \pm 0.129$ \\
F8 & $4.73 \pm 0.099$ & $5.25 \pm 0.171$ & $0.36 \pm 0.021$ & $500.3 \pm 0.804$ & $100.18 \pm 0.381$ \\
F9 & $4.70 \pm 0.071$ & $5.05 \pm 0.096$ & $0.35 \pm 0.023$ & $500.9 \pm 1.170$ & $100.12 \pm 0.109$ \\
F10 & $4.68 \pm 0080$ & $5.32 \pm 0.121$ & $0.34 \pm 0.021$ & $500.6 \pm 0.932$ & $100.12 \pm 0.186$ \\
F11 & $4.77 \pm 0.085$ & $5.13 \pm 0.149$ & $0.33 \pm 0.017$ & $500.5 \pm 1.080$ & $100.23 \pm 0.122$ \\
F12 & $4.69 \pm 0.067$ & $5.05 \pm 0.150$ & $0.37 \pm 0.026$ & $499.9 \pm 0.534$ & $100.16 \pm 0.170$ \\
\hline
\end{tabular}

(Number of experiments $n=3$, mean \pm SD)

\section{In vitro buoyancy studies}

The time taken for the tablets to rise to the surface and float is the floating lag time. The gas generated is trapped and protected within the gel, formed by hydration of the polymer, thus decreasing the density of the tablet. As the density of the tablet falls, the tablet became buoyant. The floating lag time ranged from $35 \mathrm{~s}$ to $50 \mathrm{~s}$. From the table 5 , it was found that the formulation F11 has the minimum floating lag time of $35 \mathrm{~s}$ and maximum total floating time of $15 \mathrm{~h}$ with $100.12 \%$ drug content.
Thus it was taken as the optimum formulation. Hence stability studies were carried out on F11 and there was a marginal increase of moisture content and hardness, while no change in the friability was found, showing that these changes were within the specified limits.

The effect of ingredients in the polyherbal tablet was analyzed, where HPMC contributed as the floating matrix, MCC to increase the bulk density of the tablet and sodium bicarbonate to initiate the dissolution process.

Table 5: Result of floating property of herbal tablet

\begin{tabular}{lll}
\hline Formulation code & Floating lag time (s) & Total floating duration (h) \\
\hline F1 & 44 & 5.5 \\
F2 & 55 & 3.5 \\
F3 & 50 & 6.5 \\
F4 & 52 & 4.5 \\
F5 & 45 & 6.5 \\
F6 & 40 & 5 \\
F7 & 39 & 8 \\
F8 & 42 & 5.5 \\
F9 & 37 & 12.5 \\
F10 & 40 & 10.5 \\
F11 & 35 & 15 \\
F12 & 39 & 12.5 \\
\hline
\end{tabular}

(Number of experiments $n=3$, mean)

\section{In vitro dissolution studies of prepared tablets}

The in vitro dissolution studies were conducted for all formulations in triplicate and the dissolution graph was drawn with error bars pertaining to the standard deviation of the three tests. All tablets retained their integrity throughout the study and released the drug in a controlled manner as shown in the fig. 3. Eight batches of formulations (F1-F8) which had HPMC composition up to $140 \mathrm{mg}$ had an earlier release of drug for the same amount of sodium bicarbonate. In this, F7 had the longest floating time of $8 \mathrm{~h}$. In the remaining four batches of formulations, F10 got completely dissolved at $10.5 \mathrm{~h}$ but the other three batches of F9, F11 and F12 showed floating time larger than $12 \mathrm{~h}$.

The disadvantage of the Ayurvedic formulation is the drug stability and most of the plant-based drugs are delivered in the form of film coated tablet, which has the dissolution of $97.6 \%$ at $45 \mathrm{~min}$ and to overcome this issue a new technique is required [25]. Thus from the results obtained, it was found that the bioavailability of the drug has been enhanced compared to that of the film coated tablets. 


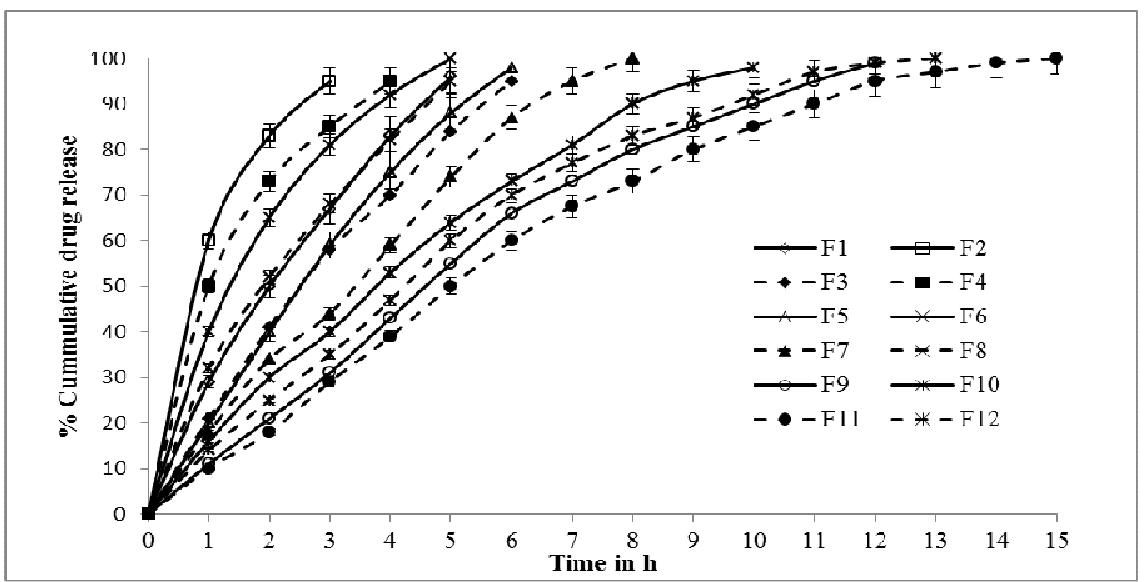

Fig. 3: In vitro dissolution profiles for different formulations, (Number of experiments $n=3$, mean \pm SD)

\section{Release kinetics}

The various kinetic models were analyzed for all the formulations. It was found from the table 6 that the optimum formulation was F11 i.e. having HPMC K4M had the minimum floating lag time and higher drug release. The optimized formulation F11 was found to follow typical Korsmeyer and Peppas model, which clearly indicated by their relatively higher $\mathrm{R}^{2}$ value of 0.9819 compared to the zero order, first order regression coefficient values and Higuchi diffusion model. The entire exponent ' $n$ ' values were found to be greater than 1 indicating that all the formulations were following Case II transport. Also, the rate constant $K_{K}$ and $n$ were 1.0492 and 1.7385 with a significance of $\mathrm{P}<0.05$.

Table 6: Dissolution kinetics analysis

\begin{tabular}{|c|c|c|c|c|c|c|c|c|c|}
\hline & \multicolumn{2}{|c|}{ Zero Order } & \multicolumn{2}{|c|}{ First Order } & \multicolumn{2}{|c|}{ Highuchi } & \multicolumn{3}{|c|}{ Korsmeyer-Peppas } \\
\hline & $\mathbf{K}_{\mathbf{0}}$ & $\mathbf{R}^{2}$ & $\mathbf{K}_{1}$ & $\mathbf{R}^{2}$ & $K_{H}$ & $\mathbf{R}^{2}$ & $\mathbf{K}_{\mathbf{K}}$ & n & $\mathbf{R}^{2}$ \\
\hline F1 & 20.37 & 0.9503 & 0.2462 & 0.8066 & 39.88 & 0.9503 & 1.4732 & 1.4661 & 0.9975 \\
\hline F2 & 34.82 & 0.6971 & 0.4673 & 0.9266 & 56.53 & 0.9879 & 1.7914 & 0.7975 & 0.9843 \\
\hline F3 & 16.83 & 0.9705 & 0.1937 & 0.7805 & 35.53 & 0.9283 & 1.3451 & 1.6621 & 0.9941 \\
\hline F4 & 26.69 & 0.7575 & 0.3376 & 0.8930 & 48.49 & 0.9853 & 1.7119 & 0.9038 & 0.9912 \\
\hline F5 & 17.33 & 0.9712 & 0.2195 & 0.8098 & 36.52 & 0.9163 & 1.3272 & 1.7576 & 0.9901 \\
\hline F6 & 23.92 & 0.8312 & 0.3087 & 0.8945 & 45.40 & 0.9814 & 1.6311 & 1.1163 & 0.9831 \\
\hline F7 & 13.95 & 0.9782 & 0.1768 & 0.7719 & 32.45 & 0.9095 & 1.2616 & 1.6978 & 0.9954 \\
\hline F8 & 20.35 & 0.9331 & 0.2408 & 0.7998 & 39.96 & 0.9625 & 1.5051 & 1.3551 & 0.9987 \\
\hline F9 & 9.12 & 0.9549 & 0.1126 & 0.8156 & 26.68 & 0.9101 & 1.0591 & 1.8220 & 0.9854 \\
\hline F10 & 11.03 & 0.9421 & 0.1350 & 0.8499 & 29.52 & 0.9398 & 1.2377 & 1.5679 & 0.9937 \\
\hline F11 & 7.97 & 0.9276 & 0.1069 & 0.8377 & 25.42 & 0.9255 & 1.0492 & 1.7385 & 0.9819 \\
\hline F12 & 9.30 & 0.8997 & 0.1267 & 0.8443 & 27.76 & 0.9419 & 1.1744 & 1.5982 & 0.9798 \\
\hline
\end{tabular}

(Number of experiments $n=3$, mean)

\section{CONCLUSION}

Pedalium murex and Tribulus terrestris were found to blend with the polymer matrix and other excipients. The herbal extracts were found to have a rich source of chemical constituents that act as a cure for various diseases. Floating was successfully achieved at the taken concentration of HPMC K4M or HPMC K15M, MCC and sodium bicarbonate. Among all the formulations, formulation F11 showed promising results releasing $100.12 \%$ with a floating lag time of $35 \mathrm{~s}$ and total floating time of $15 \mathrm{~h}$. Thus this new attempt of developing polyherbal floating effervescence tablets proves not only to be used as an effective drug release method for herbal drugs to enhance their bioactivity but also as a better replacement for film coated tablets.

\section{ACKNOWLEDGEMENT}

I would express my gratitude to the Dr. T. Sivakumar, Principal and Dr. M. Jagadeeswaran for their encouragement, support and guidance for this work and also to the department of Pharmaceutical chemistry and Department of pharmaceutics, Nandha College of Pharmacy, Erode for providing infrastructure facilities to carry out the above research

\section{CONFLICT OF INTERESTS}

Declare none

\section{REFERENCES}

1. Hill AF. Economic Botany: A textbook of useful plants and plants products; 1952.

2. Pandey G, Verma KK, Singh M. Evaluation of phytochemical, antibacterial and free radical scavenging properties of Azadirachtaindica (neem) leaves. Int J Pharm Pharm Sci 2014;6:444-7.

3. Rajashekar V, Rao EU, Srinivas P. Biological activities and medicinal properties of Gokhru (Pedalium murex L.). Asian Pac J Trop Biomed 2012;2:581-5.

4. Jayanthy A, Deepak M, Remashree AB. Pharmacognostic characterization and comparison of fruits of Tribulus terrestris L. and Pedalium murex L. Int J Herb Med 2013;1:29-34.

5. Sermakkani M, Thangapandian V. Phytochemical screening for active compounds in Pedalium murex L. Recent Res Sci Technol 2010;2:110-4.

6. Bhakuni RS, Shukla YN, Thakur RS. Flavonoids and other constituents from Pedalium murex. Phytochemistry 1992;31:2917-8. 
7. Patel DK, Kumar R, Prasad SK, Hemalatha S. Pedalium murex Linn (Pedaliaceae) fruits: a comparative antioxidant activity of its different fractions. Asian Pac J Trop Biomed 2011;1:395-400.

8. Shelke TT, Kothai R, Adkar PP, Bhaskar VH, Juvale KC, Kamble $\mathrm{BB}$, et al. Nephroprotective activity of ethanolic extract of dried fruits of Pedalium murex linn. J Cell Tissue Res 2009;9:1687-90.

9. Hashim S, Bakht T, Marwat KB, Jan A. Medicinal properties, phytochemistry and pharmacology of Tribulus Terrestris $L$. (Zygophyllaceae). Pak J Bot 2014;46:399-404.

10. Wu G, Jiang S, Jiang F, Zhu D, Wu H, Jiang S. Steroidal glycosides from Tribulus terrestris. Phytochemistry 1996;42:1677-81.

11. Kostova I, Dinchev D. Saponins in Tribulus terrestris-chemistry and bioactivity. Phytochem Rev 2005;4:111-37.

12. Zheleva-Dimitrova DI, Obreshkova DA, Nedialkov P. Antioxidant activity of Tribulus terrestris-a natural product in infertility therapy. Int J Pharm Pharm Sci 2012;4:508-11.

13. Hajmohamadi S. Physiological and pharmaceutical effects of Tribulus terrestris as a multipurpose and valuable medicinal plant. Int J Adv Biol Biomed Res 2013;1:1289-95.

14. Dileep K, Sarvesh K, Narasimha MKHHVSS. Ayurvedic formulations for the management of psychotic disorders. Int J Res Ayurveda Pharm 2012;3:655-8.

15. Witzel F, Clark KW. Inventors; Life Savers, Inc., assignee. Effervescent tablet and method. United States patent US 4,127,645; 1978 .

16. Lamba HS, Bhargava CS, Thakur MA, Bhargava SH. $\alpha-$ glucosidase and Aldose reductase inhibitory activity in vitro and anti-diabetic activity in vivo of Tribulus terrestris L.(Dunal). Int J Pharm Pharm Sci 2011;3:270-2.

17. Akiladevi D, Shanmugapandiyan P, Jebasingh D, Basak S. Preparation and evaluation of paracetamol by solid dispersion technique. Int J Pharm Pharm Sci 2011;3:188-91.
18. Aulton ME. Pharmaceutics: the science of dosage form design. Churchill livingstone; 2002.

19. Gibson M. editor. Pharmaceutical preformulation and formulation: a practical guide from candidate drug selection to the commercial dosage form. CRC Press; 2016.

20. Gupta R, Sharma P, Garg A, Soni A, Sahu A, Rai S, et al. Formulation and Evaluation of herbal effervescent granules incorporated with Calliandrahaematocephala leaves extract. Indo Am J Pharm Res 2013;3:4366-71.

21. Ashwini I, Deepthi PR, Babu AM, Bakshi V. Development of a prolongd release gastro retentive tablet formulation of levofloxacin. Int J Appl Pharm 2015;7:7-10.

22. Velivela S, Abbulu K, Vinyas M, Pati NB. Formulation and in vitro evaluation of ritonavir floating tablets by melt granulation technique. Int J Appl Pharm 2016;8:12-5.

23. Kumari SDC, Vengatesh S, Elango K, Damayanthi RD, Deattu $\mathrm{N}$, Christina P. Formulation and evaluation of floating tablets of ondansetron hydrochloride. Int J Drug Devand Res 2012; $4: 265-74$.

24. Guillory JK, Poust RI. Chemical kinetics and drug stability. Modern pharmaceutics; 2002.

25. McCabe TT, Stagner RA, Sutton Jr JE. Inventors; Burroughs Wellcome Co., assignee. Flavored film-coated tablet. United States patent US 5,098,715; 1992.

\section{How to cite this article}

- Chitra Devi Venkatachalam, Mothil Sengottian, Tamizharasi Sengodan. Formulation and evaluation of polyherbal floating effervescence tablet containing pedalium murex and tribulus terrestris fruit extracts. Int J Appl Pharm 2017;9(2):10-15. 